\title{
MEASUREMENT OF POLYETHYLENE WEAR IN CEMENTLESS TOTAL HIP ARTHROPLASTY
}

\author{
CHUN-HSIUNG SHIH, PO-CHENG LEE, JIAN-HORNG CHEN, CHING-LUNG TAI, LI-FAN CHEN, \\ J. SHIH-SHYN WU, WALTER H. CHANG
}

From Chang Gung Medical College, Taiwan, Republic of China

We made a clinical study of polyethylene wear in 240 hips of 187 patients having primary total hip arthroplasties from 1989 to 1990 , using uncemented Osteonics components, with a head size of $26 \mathrm{~mm}$. We excluded cups with anteversion of over $20^{\circ}$ and measured linear wear by a new method using a digitiser and special software of our design. Follow-up was from two to five years (mean 4.3).

The mean age at operation was $\mathbf{5 0 . 3}$ years, with more men than women (1.4:1). The mean linear wear per year was $0.15 \mathrm{~mm}$; this did not increase with the longevity of the prosthesis $(p=\mathbf{0 . 5 4})$. In 59 hips showing evidence of osteolysis, the mean linear wear rate was significantly higher at $0.23 \mathrm{~mm} /$ year $(\mathrm{p}<0.001)$. The mean linear wear rate also correlated significantly with age at the time of operation $(p=0.008)$, but we found no significant correlations with body-weight, gender, aetiology of the disease, thickness of polyethylene, or cup position.

Our new method of measurement is time-saving and reproducible. The results confirm the greater rate of linear wear of polyethylene in patients showing osteolysis and in those who are younger.

J Bone Joint Surg [Br] 1997;79-B:361-5.

Received 19 February 1996; Accepted after revision 19 November 1996

C.-H. Shih, MD, Professor and Chief

P.-C. Lee, MD

C.-L. Tai, MS, Research Engineer

L.-F. Chen, BS, Research Engineer

Department of Orthopaedic Surgery, Chang Gung Memorial Hospital,

Chang Gung Medical Centre, Number 5, Fu-Hsin, Street 333, Kweishan,

Taoyuan, Taiwan, Republic of China.

J.-H. Chen, MS, PhD, Student

Department of Physics

W. H. Chang, MS, Professor

Department of Biomedical Engineering

Chung Yuan Christian University, 22, Pu Jen Li, Chung Li, Taiwan 320,

Republic of China.

J. S.-S. Wu, PhD, Professor

Department of Mechanical Engineering, National Chung Hsing University, 250, Kuo-Kuang Road, Taichung, Taiwan 402, Republic of China.

Correspondence should be sent to Dr C.-H. Shih.

(C)1997 British Editorial Society of Bone and Joint Surgery 0301-620X/97/36630\$2.00
Polyethylene wear is a growing concern ${ }^{1-4}$ since the biological response to particulate debris is thought to be an important contributor to osteolysis and to affect the longevity of total hip arthroplasty. ${ }^{5-7}$ Retrieval studies 8,9 and measurement of wear at the bearing surface by imaging have been widely used to quantitate this in large series. ${ }^{\text {10-12 }}$ The measuring techniques have been criticised, ${ }^{13-15}$ and a new method has been developed by Devane et $\mathrm{al}^{4}$ for the three-dimensional assessment of polyethylene wear from plain radiographs. Using a digitising tablet and customwritten software, it has an accuracy of $\pm 0.15 \mathrm{~mm}$, and was validated by use of a precise acrylic phantom with a milled metal-backed acetabular component. We have used a computer-based technique designed to measure two-dimensional linear wear in the frontal plane from clinical anteroposterior (AP) radiographs, and evaluated the method for its reproducibility.

The diameter of the femoral head is known to be a factor in polyethylene wear. ${ }^{4,11,12,16}$ A $32 \mathrm{~mm}$ head produces greater volumetric wear than a $28 \mathrm{~mm}$ or $22 \mathrm{~mm}$ head, but the latter gives greater head penetration and a higher incidence of hip dislocation. The middle range is considered to have the best wear characteristics, and in our study, the femoral head had a diameter of $26 \mathrm{~mm}$.

Metal-backed acetabular components are widely used $^{17,18}$ and provide the necessary metal surface for biological fixation. Metal backing has been shown by finiteelement analysis to stiffen the polyethylene and produce a more even distribution of stress, ${ }^{19}$ but after early success, later results failed to confirm this biomechanical prediction; higher wear rates have been reported for uncemented arthroplasties. $^{2,20,21}$

We have examined changes at the bearing surface in uncemented total hip arthroplasties during a two- to fiveyear follow-up period in a single surgeon's practice $(\mathrm{C}$ HS), to estimate the wear of the polyethylene liner and to identify its related risk factors.

\section{PATIENTS AND METHODS}

We studied 240 total hip arthroplasties in 187 patients from 1989 to 1990 , all performed by the senior author (C-HS). The mean follow-up period was 4.3 years ( 2 to 5 ). All the prostheses were of the Osteonics pattern (Allendale, New 


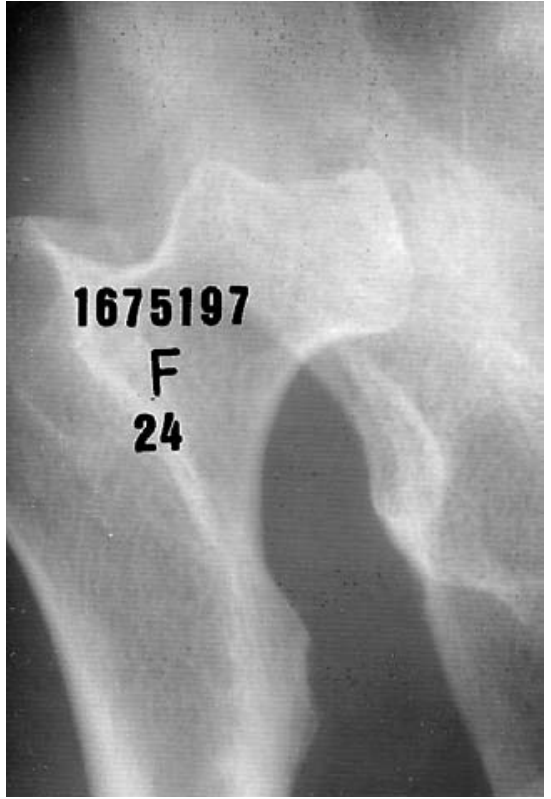

Fig. 1a

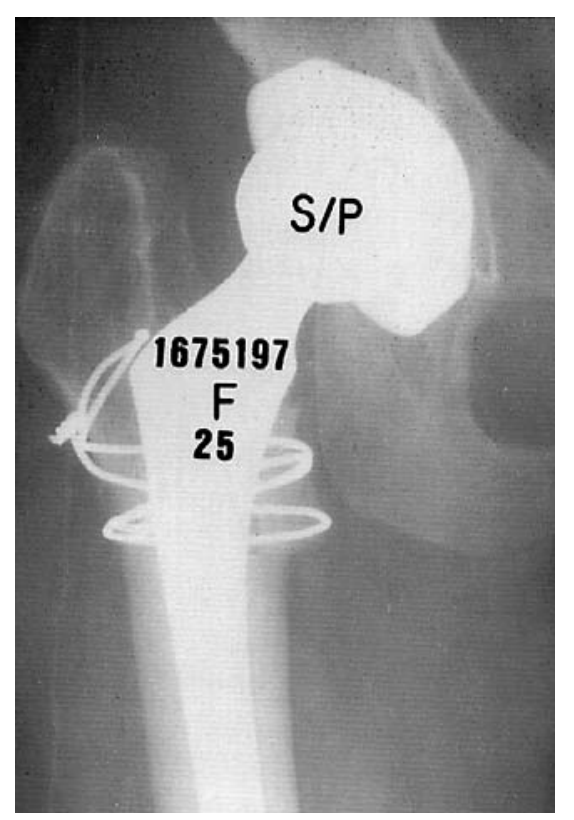

Fig. 1b

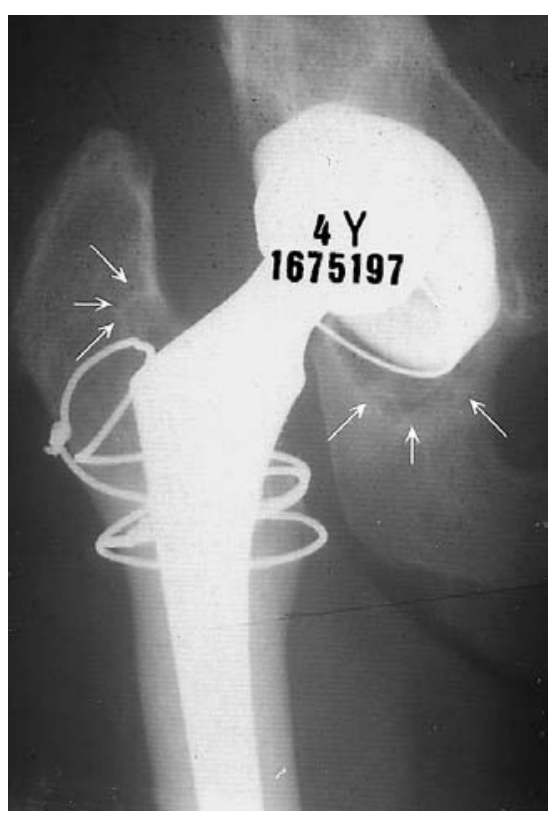

Fig. 1c

Radiographs of a 24-year-old woman before total hip arthroplasty (a), three months after (b) and at four years showing marked polyethylene wear and two areas of osteolysis (arrows) (c).

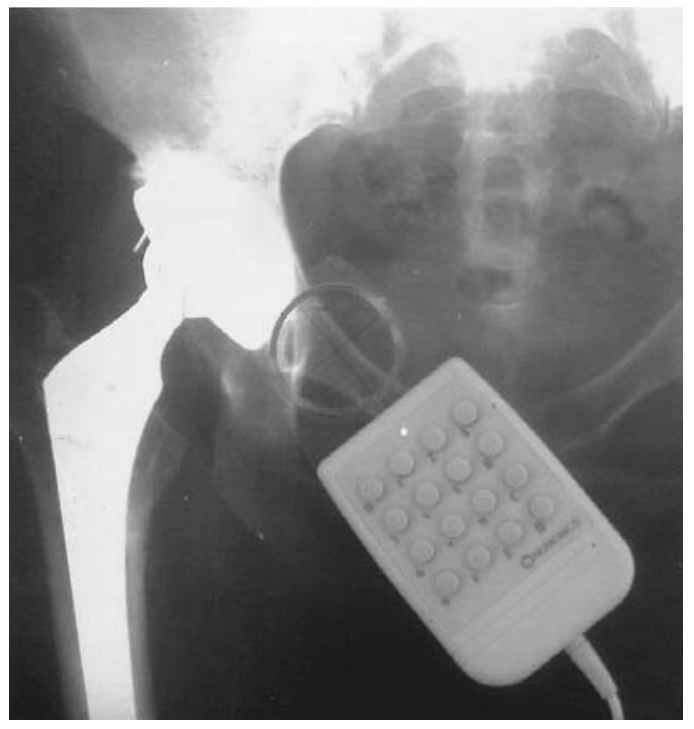

Fig. 2a

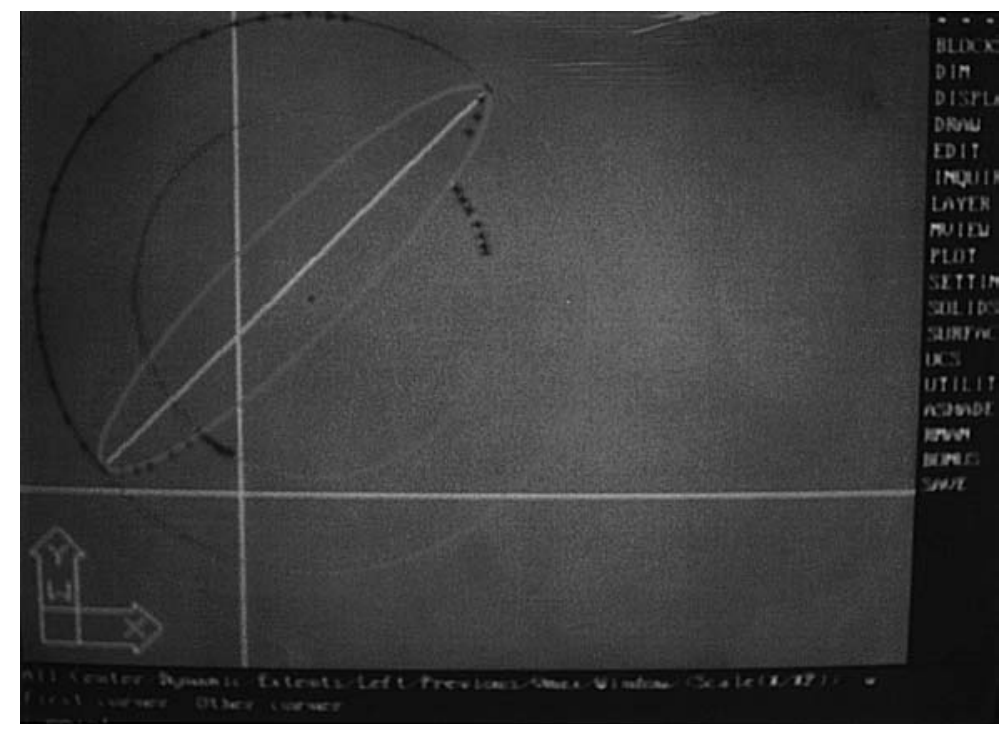

Fig. 2b

From the standard AP radiograph, points are selected at the front and back of the opening of the cup, the head, and the margin of the cup using a digitiser (a). The computer system and software convert the data points after correction for magnification into two circles and one ellipse, before calculating the required measurements (b).

Jersey), with porous-coated titanium shells, modular polyethylene liners, and a cobalt-chromium alloy femoral head and stem (Omnifit). The femoral components had a plasmasprayed porous coating in their proximal third and a modular femoral head of $26 \mathrm{~mm}$ in diameter. The mean age at operation was 50.3 years (19 to 82 ) and the male to female ratio was $1.4: 1$. Sockets showing more than $20^{\circ}$ of anteversion were excluded, because in our previous study calculation of the polyethylene wear has been shown to be influenced by anteversion. $^{22}$

Standard AP and lateral radiographs were taken on nonportable equipment using the same technique for all patients. ${ }^{23}$ Poor control of the relationship between the AP and lateral radiographs and the poor quality of some lateral views led us to use only the consecutive annual AP films to measure head displacement (Fig. 1). The data points which we digitised were from the acetabular cup-bone interface, the surface contour of the head and the opening of the cup 
Table I. Reproducibility of the digitising technique

\begin{tabular}{|c|c|c|c|}
\hline Observation & $\begin{array}{l}\text { Number of } \\
\text { observations }\end{array}$ & $\begin{array}{l}\text { Standard } \\
\text { deviation }\end{array}$ & $\begin{array}{l}95 \% \\
\text { confidence limits }\end{array}$ \\
\hline \multicolumn{4}{|c|}{ Linear wear $(\mathrm{mm})$} \\
\hline Intraobserver & 10 & 0.0047 & \pm 0.0034 \\
\hline Interobserver & 10 & 0.0080 & \pm 0.0057 \\
\hline \multicolumn{4}{|l|}{ Version (degrees) } \\
\hline Intraobserver & 10 & 0.37 & \pm 0.26 \\
\hline Interobserver & 10 & 0.52 & \pm 0.37 \\
\hline \multicolumn{4}{|c|}{ Inclination (degrees) } \\
\hline Intraobserver & 10 & 0.17 & \pm 0.12 \\
\hline Interobserver & 10 & 0.38 & \pm 0.27 \\
\hline
\end{tabular}

(AccuGrid, Model, Light Box 012581; Numonics Corporation, Montgomeryville, Pennsylvania), using our own formula and software program to measure linear wear. ${ }^{22}$ This uses custom-written CAD software with 64 bit-precision, corrects for magnification, and converts the data points into two circles and one ellipse correlatively. One circle represents the outer surface of the acetabular component and the other the prosthetic femoral head. The ellipse represents the opening of the cup (Fig. 2). The computer then calculates the linear wear, the angle of version of the cup, its inclination and the direction of socket wear.

The annual wear rate for each hip was the difference in wear calculated from two consecutive radiographs, divided by the time interval. The metal-backed acetabulum partly obscured full visualisation of the femoral head, but this did not prevent accurate determination of its centre because of the relative transparency of the titanium shell on plain radiographs, regardless of version and inclination. For greater accuracy, all data used in the operating processes of the software program were of a double-precision type which allocated eight bytes of memory.

We defined osteolysis as any discrete area of endosteal scalloping greater than $3 \mathrm{~mm}$ in any direction which was adjacent to the femoral or acetabular component on serial radiographs, but not on the immediate postoperative film. Reproducibility and statistics. The same AP radiograph was digitised by ten observers independently to assess interobserver variance. Intraobserver variance was assessed by having one observer digitising the same radiograph ten
Table II. Comparison of osteolysis versus mean polyethylene

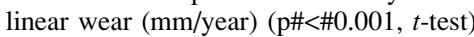

\begin{tabular}{lcl}
\hline & Number & Mean polyethylene wear rate \\
\hline Osteolysis & 59 & $0.23 \pm 0.15$ \\
No osteolysis & 181 & $0.13 \pm 0.088$ \\
\hline
\end{tabular}

times. Statistical analysis determined the intraobserver and interobserver variances of this new method and validated its reproducibility. The relationship between polyethylene wear rate and various clinical and radiological factors was evaluated either by linear regression analysis or by the $t$ test.

\section{RESULTS}

The intraobserver and interobserver variability for the digitising technique used to evaluate linear wear was insignificant (Table I).

The mean linear wear rate in the whole series was $0.154 \mathrm{~mm}$ per year, and did not increase significantly with time $(p=0.54)$. It correlated significantly in hips showing osteolysis (Table II), in which the rate was $0.23 \mathrm{~mm} /$ per year. It was also significantly correlated with the age of the patient at the time of operation $(p=0.008$, Fig. 3). We found no significant correlations with body-weight, gender, aetiology of the disease, thickness of the polyethylene or cup position.

\section{DISCUSSION}

Excessive polyethylene wear and particle production are thought to be important contributors to osteolysis and aseptic loosening. ${ }^{9,24,25}$ The earliest wear measurements of acetabular components were performed by Charnley and Cupic $^{26}$ on early Teflon sockets, and osteolysis around cemented femoral components was first reported by Charnley and $\mathrm{Cupic}^{26}$ and Harris et al. ${ }^{27}$ Osteolysis also occurs around stable uncemented prostheses. ${ }^{28,29}$

The main cause of osteolysis in cementless total hip arthroplasty is believed to be secondary to wear of the

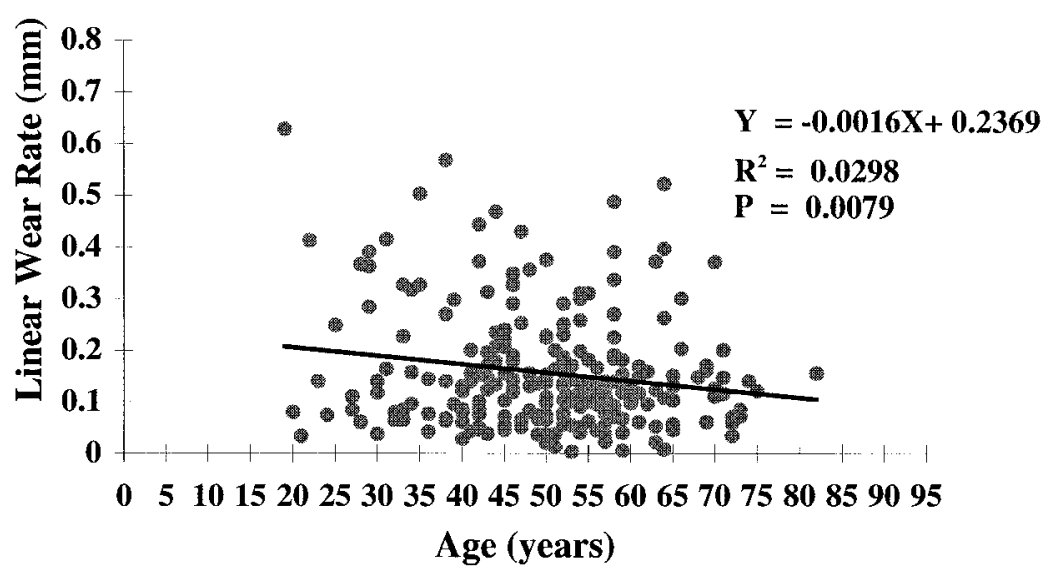

Fig. 3

Regression analysis of patient age related to linear wear of polyethylene. 
acetabular liner ${ }^{28-30}$ and the longevity of the implant may well be limited by bone destruction initiated by minute wear particles. Reduction of the number of these is therefore important, and some recent investigations have focused on better understanding of the performance of an acetabular liner, in terms of wear rate and related risk factors. ${ }^{1,2,31,32}$ Series of postmortem retrievals would be an optimal method of study, but are impractical on a large scale. Radiological measurement of linear wear has limitations, but serial radiographs from one institution, of a single surgeon's practice for long periods of use of similar techniques, are probably the next best available source of longterm data.

Charnley and Cupic $^{26}$ reported a nine- to ten-year follow-up study on low-friction arthroplasty in 1973, measuring the position of a wire marker in the acetabular component on single radiographs, to a claimed accuracy of $0.5 \mathrm{~mm}$. Clarke and Amstutz ${ }^{33}$ evaluated the techniques of Charnley, and concluded that the use of successive radiographs was more accurate. Griffith et al ${ }^{34}$ compared radiological with direct measurement and found an average error of $0.2 \mathrm{~mm}$. Livermore et $\mathrm{al}^{12}$ reported a method using a transparent template with concentric circles, compass and calliper. They compared direct and radiological measurement, and reported an average error of $0.075 \mathrm{~mm}$. Kabo et $\mathrm{al}^{9}$ confirmed that measurement of linear wear from AP radiographs gave reasonable estimates and Bankston et al ${ }^{35}$ further evaluated the Livermore method, reporting an error of less than $0.2 \mathrm{~mm}$, not statistically different from direct measurement. They concluded that although wear in the sagittal plane did occur, it did not affect the accuracy of measurement in their study. Devane et $\mathrm{al}^{4}$ were the first to report a three-dimensional technique using a digitiser and custom-written software, validating it by measuring a precise acrylic phantom and a milled metal-backed acetabular component. Their method has an accuracy of $\pm 0.15 \mathrm{~mm}$ with good reproducibility. They found a two-dimensional displacement of the femoral head in the AP radiographs of $0.15 \mathrm{~mm} /$ year which was comparable with that obtained by previous studies. Their rate for three-dimensional femoral head displacement, however, measured in both AP and lateral radiographs by the same technique was significantly higher at $0.264 \mathrm{~mm}$ per year. This suggests that twodimensional measurements underestimate the rate of wear, because they cannot measure displacement away from the plane of an AP radiograph. The accuracy of such measurements warrants more work on the relationship between radiological and true wear.

Instead of using a transparent overlay, compass, and calliper, we employed a computer-based system and a digitiser. The custom-written software can correct for radiological magnification, estimate the two-dimensional linear wear, the angle of version of the cup and its inclination and the direction of socket wear. In our study, we excluded sockets with more than $20^{\circ}$ anteversion $^{22}$ as did Schuller. ${ }^{36}$ The major advantages of our method are the short learning curve, the speed and accuracy of $0.0125 \mathrm{~mm}$, which is much better than $0.05 \mathrm{~mm}$ using a manual calliper. ${ }^{1,2}$ Our interobserver and intraobserver variances were statistically insignificant.

There are several reports of polyethylene wear in cemented acetabular components, but few for uncemented metalbacked cups. Using the technique of Livermore et al, ${ }^{12}$ Hernandez et $\mathrm{al}^{2}$ first reported a mean linear wear rate for uncemented acetabular cups of $0.22 \mathrm{~mm}$ per year. Results obtained by identical methods for cemented acetabular components showed a significant increase in polyethylene wear in the uncemented metal-backed cups, with even worse results when the femoral component was also uncemented. They discuss three factors: the uncemented metalbacked cups, machined polyethylene, and titanium femoral components. In our series, all components were uncemented but the femoral components were chrome-cobalt alloy. The mean linear wear rate was $0.154 \mathrm{~mm}$ per year, slightly greater than the reported rate for cemented cups.

Factors affecting polyethylene wear in total hip arthroplasty include the size and material of the femoral head, the physical properties of polyethylene itself, ${ }^{3}$ the conformity of the articulation, ${ }^{31}$ metal backing, ${ }^{1}$ cementing ${ }^{37}$ and various host factors. Kim and $\mathrm{Kim}^{28}$ reported a statistically significant relationship between patient age and excessive wear, but found no link with diagnosis, body-weight, or gender. Griffith et $\mathrm{al}^{34}$ showed correlations of age and gender with increased wear, and Rimnac et $\mathrm{al}^{8}$ also found increased wear in younger patients. Nashed et $\mathrm{al}^{37}$ found a positive correlation in younger and male patients, but not for body-weight. Devane et al $^{4}$ reported a tendency for the younger patients to show more femoral-head displacement and a greater volume of polyethylene wear debris.

We have shown that linear wear rate correlated significantly with age and with osteolysis, but not with bodyweight, gender, diagnosis, thickness of polyethylene liner, and the position of cups. Our results confirm the clinical impression that polyethylene wear correlates with the incidence of osteolysis and with younger age.

This work was funded by the National Science Council of Taiwan, Republic of China.

No benefits in any form have been received or will be received from a commercial party related directly or indirectly to the subject of this article.

\section{REFERENCES}

1. Cates HE, Faris PM, Keating EM, Ritter MA. Polyethylene wear in cemented metal-backed acetabular cups. J Bone Joint Surg [Br] 1993;75-B:249-53.

2. Hernandez JR, Keating EM, Faris PM, Meding JB, Ritter MA. Polyethylene wear in uncemented acetabular components. J Bone Joint Surg [Br] 1994; 76-B:263-6.

3. Bankston AB, Cates H, Ritter MA, Keating EM, Faris PM. Polyethylene wear in total hip arthroplasty. Clin Orthop 1995; 317:7-13.

4. Devane PA, Bourne RB, Rorabeck CH, Hardie RM, Horne JG. Measurement of polyethylene wear in metal-backed acetabular cups. Clin Orthop 1995;319:303-16.

5. Dorr LD, Bloebaum R, Emmanual J, Meldrum R. Histologic, biochemical and ion analysis of tissue and fluids retrieved during total hip arthroplasty. Clin Orthop 1990;261:82-95. 
6. Howie DW. Tissue response in relation to type of wear particles around failed hip arthroplasties. J Arthroplasty 1990;5:337-48.

7. Schmalzried TP, Kwong LM, Jasty M, et al. The mechanism of loosening of cemented acetabular components in total hip arthroplasty: analysis of specimens retrieved at autopsy. Clin Orthop 1992;274:60-78.

8. Rimnac CM, Wilson PD Jr, Fuchs MD, Wright TM. Acetabular cup wear in total hip arthroplasty. Orthop Clin North Am 1988;19:631-6.

9. Kabo JM, Gebhard JS, Loren G, Amstutz H. In vivo wear of polyethylene acetabular components. J Bone Joint Surg [Br] 1993; 75-B:254-8.

10. Charnley J, Halley DK. Rate of wear in total hip replacement. Clin Orthop 1975;112:170-9.

11. Wroblewski BM. Direction and rate of socket wear in Charnley lowfriction arthroplasty. J Bone Joint Surg [Br] 1985;67-B:757-61.

12. Livermore J, Ilstrup D, Morrey B. Effect of femoral head size on wear of the polyethylene acetabular component. J Bone Joint Surg [Am] 1990;72-A:518-28.

13. Clarke IC, Black K, Rennie C, Amstutz HC. Can wear in total hip arthroplasties be assessed from radiographs? Clin Orthop 1976; 121:126-42.

14. Rose RM, Nusbaum HJ, Schneider H, et al. On the true wear rate of ultra high-molecular-weight polyethylene in the total hip prosthesis. J Bone Joint Surg [Am] 1980;62-A:537-49.

15. Ilchmann T, Franzen H, Mjöberg B, Wingstrand H. Measurement accuracy in acetabular cup migration: a comparison of four radiologic methods versus roentgen stereophotogrammetric analysis. J Arthroplasty 1992;7:121-7.

16. Ritter MA, Stringer EA, Littrell DA, Williams JG. Correlation of prosthetic femoral head size and/or design with longevity of total hip arthroplasty. Clin Orthop 1983;176:252-7.

17. Woolson ST, Maloney WJ. Cementless total hip arthroplasty using a porous-coated prosthesis for bone ingrowth fixation. $J$ Arthroplasty 1992; 7:381-8

18. Heekin RD, Callaghan JJ, Hopkinson WJ, Savory CG, Xenos JS. The porous-coated anatomic total hip prosthesis, inserted without cement: results after five to seven years in a prospective study. $J$ Bone Joint Surg [Am] 1993;75-A:77-91.

19. Carter DR. Finite-element analysis of a metal-backed acetabular component. In:The Hip. Proc 11th Open Scientific Meeting of the Hip Society. St Louis, etc: CV Mosby Co, 1983;216-28.

20. Mattingly DA, Hopson CN, Kahn A, Giannestras NJ. Aseptic loosening in metal-backed acetabular components for total hip replacement: a minimum five-year follow-up. J Bone Joint Surg [Am] 1985;67-A:387-91.
21. Berry DJ, Barnes CL, Scott RD, Cabanela ME, Poss R. Catastrophic failure of the polyethylene liner of uncemented acetabular components. J Bone Joint Surg [Br] 1994;76-B:575-8.

22. Chen JH, Wu SS, Chang WH, Shih CH. An algorithm for estimating the accurate polyethylene wear. J Orthop Surg ROC 1996;13:59-72.

23. Amstutz HC, Ouzounian T, Grauer D, et al. The grid radiograph: a simple technique for consistent high-resolution visualization of the hip. J Bone Joint Surg [Am] 1986;68-A:1052-6.

24. Betts F, Salvati E, Bansal M. Debris levels and histological grading of tissues from revision total hip arthroplasties Trans Orthop Res Soc 1992; $17: 75$.

25. McKellop HA, Campbell P, Park SH, et al. The origin of submicron polyethylene wear debris in total hip arthroplasty. Clin Orthop 1995; 311:3-20.

26. Charnley J, Cupic Z $\mathbf{Z}$. The nine and ten year results of the low-friction arthroplasty of the hip. Clin Orthop 1973;95:9-25.

27. Harris WH, Schiller AL, Scholler JM, Freiberg RA, Scott R. Extensive localised bone resorption in the femur following total hip replacement. J Bone Joint Surg [Am] 1976;58-A:612-8.

28. Kim Y-H, Kim VEM. Uncemented porous-coated anatomic total hip replacement. J Bone Joint Surg [Br] 1993;75-B:6-13.

29. Xenos JS, Hopkinson WJ, Callaghan JJ, Heekin RD, Savory CG. Osteolysis around an uncemented cobalt chrome total hip arthroplasty. Clin Orthop 1995;317:29-36.

30. Cooper RA, McAllister CM, Borden LS, Bauer TW. Polyethylene debris-induced osteolysis and loosening in uncemented total hip arthroplasty: a cause of late failure. J Arthroplasty 1992;7:285-90.

31. Bartel DL, Bicknell VL, Wright TM. The effect of conformity, thickness and material on stresses in ultra-high molecular weight components for total joint replacement. J Bone Joint Surg [Am] 1986;68-A:1041-51.

32. Cuckler JM, Bearcroft J, Asgian CM. Femoral head technologies to reduce polyethylene wear in total hip arthroplasty. Clin Orthop 1995; 317:57-63.

33. Clarke IC, Amstutz HC. Validity of X-ray wear-measurement. Trans Orthop Res Soc 1976;1:80-80.

34. Griffith MJ, Seidenstein MK, Williams D, Charnley J. Socket wear in Charnley low friction arthroplasty of the hip. Clin Orthop 1978; 137:37-47.

35. Bankston AB, Keating EM, Ranawat CS, Faris PM, Ritter MA. Comparison of polyethylene wear in machined versus moulded polyethylene. Clin Orthop 1995;317:37-43.

36. Schuller HM, Marti RK. Ten-year socket wear in 66 hip arthroplasties: ceramic versus metal heads. Acta Orthop Scand 1990;61:240-3.

37. Nashed RS, Becker DA, Gustilo RB. Are cementless acetabular components the cause of excess wear and osteolysis in the total hip arthroplasty? Clin Orthop 1995;317:19-28. 